\title{
If You Don't Believe It, Don't Disrespect It! Superstitious Beliefs of Thais
}

\author{
Dr. Chaiyaset Promsri
}

\author{
Faculty of Business Administration, Rajamangala University of Technology Phra Nakhon, Bangkok, Thailand \\ Corresponding email: Chaiyaset.p@rmutp.ac.th
}

\begin{abstract}
The objectives of this study were: 1)to describe superstitious attitude and behaviors; 2)to examine level of superstitious beliefs of Thais; and 3) to compare mean differences between people with different origins (Bangkok and upcountry). Twenty-five MBA students were asked to complete the superstitious beliefs scale measurement for data collection. This scale measurement was newly developed based on the information about Thai superstitious beliefs retrieved on the Internet. The reliability of coefficient was conducted to ensure the quality of scale measurement. The alpha score of 0.916 indicated a high internal consistency of the measure. The results of this study showed that the total mean score of superstitious beliefs was at a high level. In addition, the findings also found no statistically significant differences in level of superstitious beliefs between participants who were from different origins (Bangkok and upcountry). Discussions, limitations, and recommendations for further studies were also conferred. Keywords - Superstitious beliefs, Superstition, Thai Beliefs.
\end{abstract}

\section{INTRODUCTION}

Even though Thai society is experiencing a digital age and gearing toward the high income country in a near future based on Thailand 4.0 policy of military regime, numerous people in this country are still superstitious and sometimes bond their superstitious beliefs with the success of their lives. Previous research indicated that superstitious beliefs can be used to reduce anxiety and stress particularly in a situation that individuals have no control over events or faced uncertainty (Markel, 2005; Futrell, 2011; Shrivastav, 2017). People tend to carry out superstitious belief when they have irrational fear of unknown, feeling of uncertainty, fear and stress, and need for security (Mutlu, Öntürk, Zorba, Karafil, Yuldiz, \&Kartal, 2016). This practice may be considered as the proper way for some people to decrease their stresses and anxieties. However, the major reason of individuals in today's society to follow superstitious beliefs is to gain good lucks and ward off bad lucks if they regard those beliefs. In short, superstitious beliefs are used as a replacement to instrumental acts that individuals should have desired to accomplish in order to influence the situation (Saenko, 2005).

Despite all the technological and scientific progresses in the society nowadays, people in all societies and cultures still tend to have some forms of superstitious behaviors, regardless of the economic status or literacy (Dayal, 2015). There is no exception for Thai culture, which superstition is considered as part of people lives (Proebst, 2017). Various common and tradition superstitious beliefs of Thais still exist such as "a person should not turn his/her head to the west because it is a direction of the dead, and will make him/her a nightmare" or "it is not appropriate to wear black to visit the patient because black is a symbol of grief and death." However, there was no empirical evidence to designate the level of superstitious beliefs and behaviors of Thais. According to past studies in superstitious beliefs of Thais, many of them have placed an emphasis on exploring relationships between superstitions and specific variables such as job performance (Charensukmongkol, 2017) and risk-taking behaviors (Chinchanachokchai, Pusaksrikit, \& Pongsakornrungsilp, 2016). Furthermore, some research has paid its attention on specific area of superstitions such as superstitions regarding animals (Parinyaporn, 2016). Among these studies, most of them did not specifically report the level of superstitious beliefs of Thais. Therefore, this study aimed at examining the level of superstitious behavior and beliefs of Thais. Although past research in superstitious beliefs have paid its attention on studying the relationship between socio-demographic variables and superstitions, only gender, age, education, religious believes, income, and ethnicity have been focused (Rabiei, Ghasemi, Arzani, 2013; Zad, 2014; Dayal, 2015; Vijay, Tripathi, \& Vijay, 2017). Despite superstitious beliefs are viewed as a phenomenon that happens specifically based on the culture (Kramer \& Block, 2008), the study on different origins of people who are in the same nation has been ignored.In the light of this, this present study also attempted to place more emphasis on comparing differences in superstitious beliefs of Thais according to their origins. 


\section{LITERATURE REVIEWS}

Superstitious belief is defined as an irrational belief that specific events happened in a way that cannot be explained by a scientific reason (Huque \& Chowdhury, 2007). Lakshmikanth and Hema (2016) noted that superstition is a belief in something uncritically without substantiation and proof. When individuals habitually have a robust superstitious beliefs about a phenomenon they can explain exactly what happened, but they cannot rationally elucidate the occurrence of the incidents (Kashiha, 2015). Psychologists described that superstition is a form of magical thinking, which Freud labels in the annual stage of psychosexual stage theory (Vijay, Tripathi,\& Vijay, 2017). Generally, superstitions can be distinguished into two types, which are superstitions that are considered good for individuals, if they follow it will bring them good lucks; and superstitions that are considered bad for individuals, which need to escape in orderto prevent bad lucks. In addition, superstitious beliefs are sometimes considered as a negative mechanism affecting on social well-being of individuals in society when they are tied to financial risk-taking and gambling behaviors (Chinchanachokchai, Pusaksrikit, \& Pongsakornrungsilp, 2016). However, in Thai society, there is a favorite phrase regarding superstitionsthat people usually said as quoted"if you don't believe it, don't disrespect it." This statement truly reflects a blind belief of Thais. Vijay, Tripathi, and Vijay (2017) said that superstition is a universal phenomenon. People in different cultures and societies believe in distinguished superstitions. According to this assumption, this present study attempted to examine whether Thais who are from different origins (Bangkok and upcountry) would have a difference in superstitious beliefs. Thus, the research hypothesis was proposed as "was there a statistically significant difference in superstitious beliefs between people with different origins?"

\section{METHODOLOGY}

Data were collected from MBA students at a public university in Bangkok, Thailand. Twenty-five graduate students agreed to participate in this study. A newly scale measurement of superstitious beliefs was developed using information about Thai superstition retrieved from the Internet. Key words used to search for information about superstitious beliefs of Thais were confined to "Thai superstition", "Thai superstitious beliefs", Thai superstitious behaviors", and "superstition of Thai people." After searching for superstitious beliefs of Thais on the search engine, the variety of superstitions in Thai culture were found. However, many of superstitious beliefs have already obsoleted and been forgotten by people in society. On the other hand, numerous Thai superstitious beliefsare deeply rooted in people mind. Hence, the researcher had listed all Thai superstitious beliefs, and sent the lists to three experts in this field to review and provide the substantive comments to finalize which superstitious beliefs should be omitted or remained. After reviewing, there are twenty superstitious beliefs of Thais remained as the experts believed that Thai people still follow these beliefs nowadays. These twenty superstitious beliefs were used to develop the scale measurement in which validity and reliability of coefficients were conducted in order to ensure the quality of scale measurement. Firstly, index objective congruence (IOC) method was as ses sed by three experts in area of social sciences to ensure the content validity of this scale. The IOC score of each item in this scale indicated that no item received score less than 0.5 , which can be interpreted that this scale had a strong validity. Secondly, reliability with Cronbach's alpha test was run to guarantee the internal consistency of the measure. The alpha score of 0.916 indicated that this scale was acceptable since the alpha scorewas greater than 0.7 , according to Nunnally (1978).Lastly, to examine superstitious attitude and behaviors and the level of superstitious beliefs of Thais, descriptive statistics including frequency, percentage, arithmetic mean, and standard deviation were employed. The interpretation of the score for superstitious beliefs is based on the analysis of mean average score proposed by Best (1997), which describes as follows:

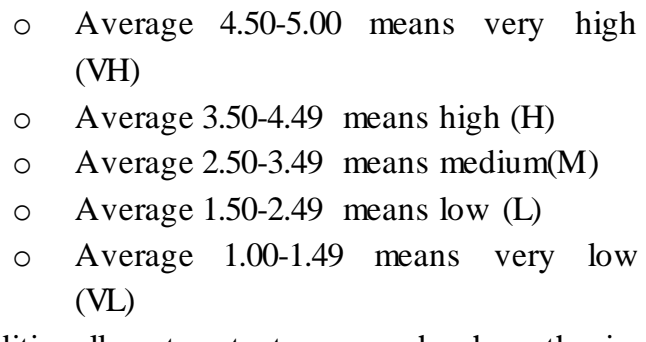

Additionally, to test research hypothesis, independent samples t-test was used to examine whether there was statistically significant difference in superstitious beliefs between people with different origins (Bangkok and upcountry).

\section{RESULTS}

The result of demographic factors of sample respondents analysis indicated that the majority of respondents was female (64\%) with age between 20-30 years $(60 \%)$, and many of them earned approximately $15,001-25,000$ baht per month (44\%). Almost a half of them worked as a government officer (48\%). Regarding their origin, more than a half of respondents are from Bangkok (56\%), and the rest of them are from upcountry $(44 \%)$. 
In addition, this study also asked participants about their superstitious attitude and behaviors through three distinctive questions including 'beliefs in superstition', 'frequency of merit making', and 'frequency of horoscope reading.' Results showed that 68 percent of respondents agreed with the saying "if you don't believe it, don't disrespect it" while 32 percent reported that they neither agreed nor disagreed (See Figure 1).

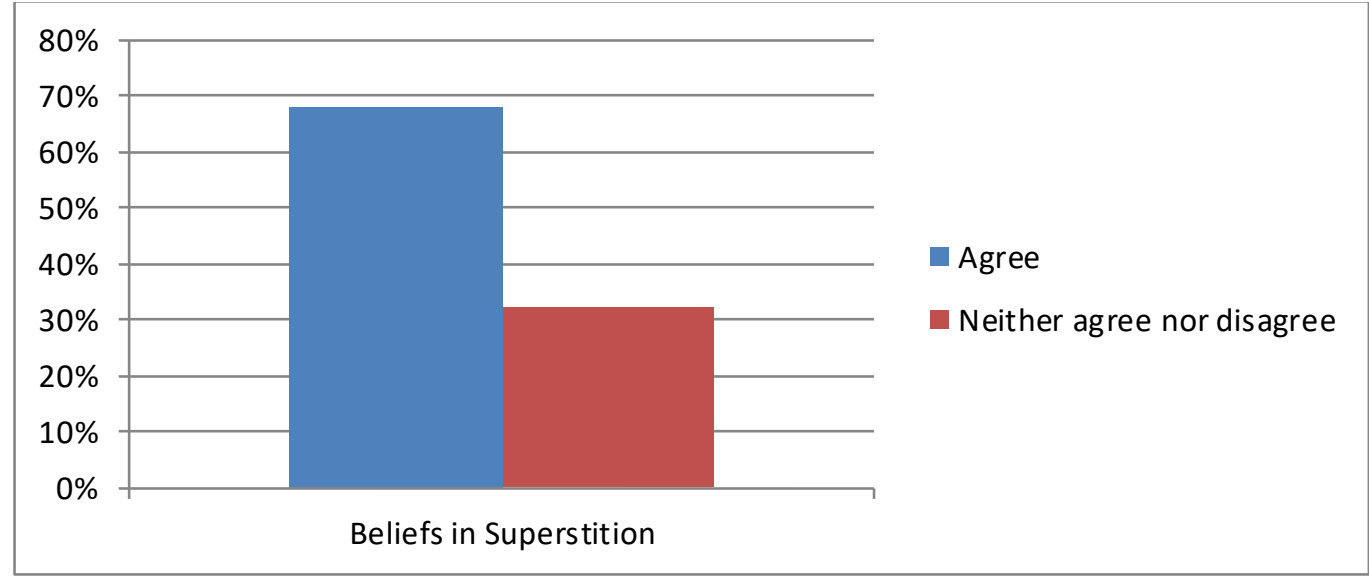

Fig.1: Attitude on "Ifyou don't believe it, don't disrespect it"

For a frequency of merit making, almost a half of respondents reported that they seldom made merit (48\%) whereas only 4 percent of this group made merit every day. Figure 2 showed the percentage of merit making frequency rated by respondents.

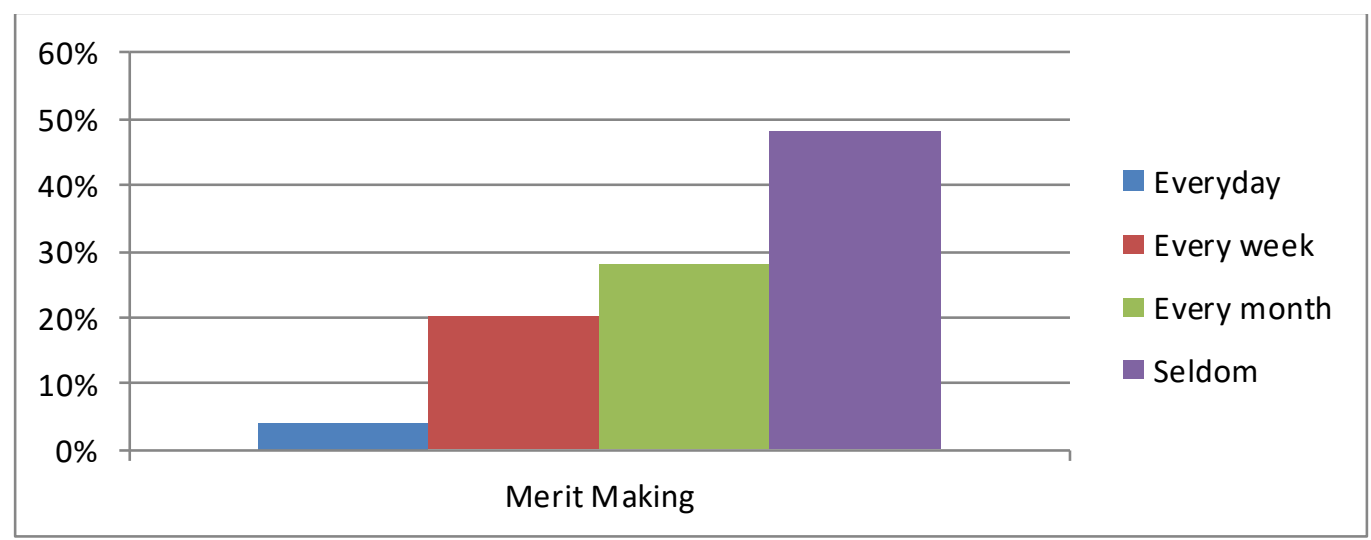

Fig.2: Percentage of Merit Making Frequency

Relating to horoscope reading, 36 percent of respondents reported that they read it once a month. Figure 3 demonstrated the percentage of horoscope reading frequency of respondents.

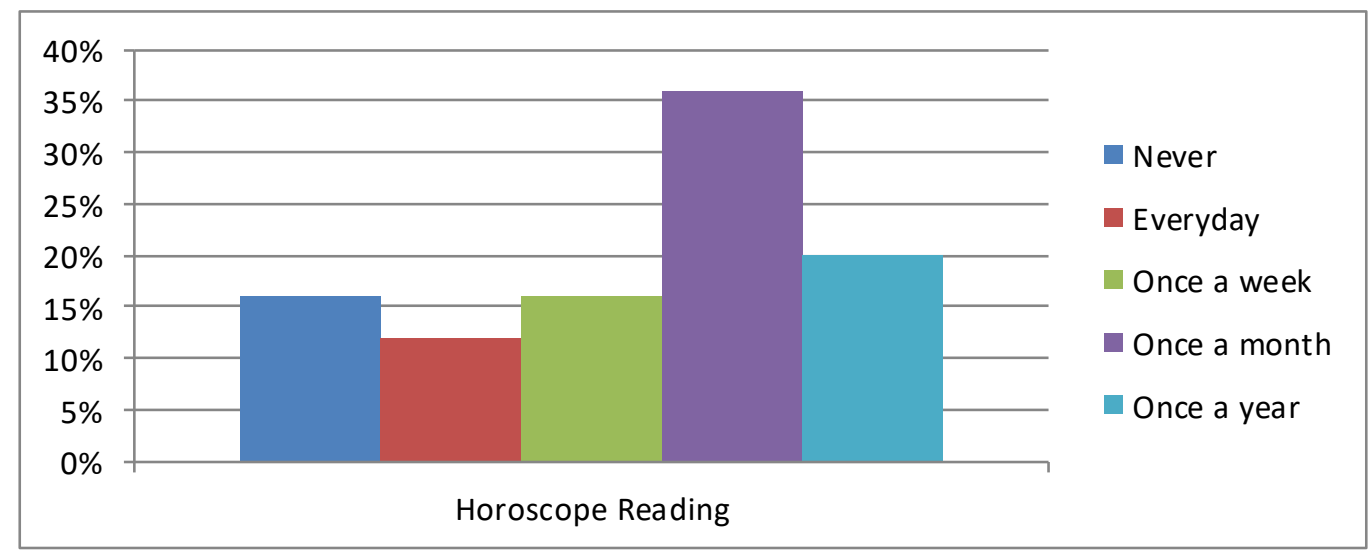

Fig.3: Percentage of Horoscope Reading Frequency 
Table 1 displayed the mean scores of 20-item of superstitious beliefs rated by the graduate students at a public university in Bangkok, Thailand. The total mean score of superstitious beliefs was at a high level $(\mathrm{M}=$ 2.85 , S.D. $=.641)$. The measurement of superstitious beliefs of respondents demonstrated that item\#10 "should not turn your head to the west because it is a direction of the dead, and it will make you a nightmare" had the highest mean score $(\mathrm{M}=3.48$, S.D. $=.962)$. The second highest mean score of superstitious beliefs was item\# 15

Table.1: Means and Standard Deviations of Superstitious Beliefs

\begin{tabular}{|c|c|c|c|c|}
\hline Questions & Mean & S.D. & Results & Ranks \\
\hline $\begin{array}{l}\text { 1. It is not appropriate to wear black to vis it the patient because black } \\
\text { is a symbol of grief and death. }\end{array}$ & 3.32 & 1.069 & $\mathrm{M}$ & 3 \\
\hline $\begin{array}{l}\text { 2. If a lizard makes a sound, one should not leave home because one } \\
\text { may experience misfortunes. }\end{array}$ & 2.64 & .907 & $\mathrm{M}$ & 14 \\
\hline $\begin{array}{l}\text { 3. If the scree crosses the roof, it will bring the bad luck because it is } \\
\text { a symbol of inauspiciousness. }\end{array}$ & 3.00 & 1.040 & $\mathrm{M}$ & 8 \\
\hline $\begin{array}{l}\text { 4. If one hears strange sounds at night, do notres pond because it is } \\
\text { believed that outlandish sounds represent evils or spirits that come to } \\
\text { kidnap. }\end{array}$ & 3.16 & 1.027 & $\mathrm{M}$ & 5 \\
\hline $\begin{array}{l}\text { 5. Do not have a haircut on Wednesday because it will bring a bad } \\
\text { luck to life. }\end{array}$ & 2.48 & 1.159 & $\mathrm{~L}$ & 18 \\
\hline 6. A bad luck will occur if left eye spasms. & 2.68 & 1.249 & $\mathrm{M}$ & 13 \\
\hline $\begin{array}{l}\text { 7. Do not use a broken comb. If a comb is broken while combing, a } \\
\text { bad luck will occur. }\end{array}$ & 2.84 & 1.106 & $\mathrm{M}$ & 10 \\
\hline $\begin{array}{l}\text { 8. If bees make nest in a house area, it will bring a good luck to a } \\
\text { landlord. }\end{array}$ & 3.20 & .816 & $\mathrm{M}$ & 4 \\
\hline $\begin{array}{l}\text { 9. Should not sweep the house at night, because it will be sweep all } \\
\text { money accumulated since the morning out of the house. }\end{array}$ & 2.32 & .900 & $\mathrm{~L}$ & 19 \\
\hline $\begin{array}{l}\text { 10. Should not turn your head to the west because it is a direction of } \\
\text { the dead, and it will make you a nightmare. }\end{array}$ & 3.48 & .962 & $\mathrm{M}$ & 1 \\
\hline 11. Do not clip one's nails at night as it will disturbancestors'spirits. & 2.28 & .979 & $\mathrm{~L}$ & 20 \\
\hline $\begin{array}{l}\text { 12. Do not give handkerchiefs as gifts to others because it is } \\
\text { ominous, which may bring sorrow or quarrel. }\end{array}$ & 2.48 & .822 & $\mathrm{M}$ & 17 \\
\hline $\begin{array}{l}\text { 13. If one dreams to have a broken tooth, it means losing a close } \\
\text { pers on. }\end{array}$ & 3.12 & 1.013 & $\mathrm{M}$ & 6 \\
\hline 14. If a bird poops on your head, it will bring a bad luck. & 2.72 & 1.173 & M & 12 \\
\hline $\begin{array}{l}\text { 15. If one wears an amulet, it is believed not to walk under the } \\
\text { clothes line. }\end{array}$ & 3.44 & 1.003 & $\mathrm{M}$ & 2 \\
\hline $\begin{array}{l}\text { 16. Do not tap a rice dish while eating because it brings evils to join } \\
\text { the dining }\end{array}$ & 3.00 & 1.000 & $\mathrm{M}$ & 7 \\
\hline $\begin{array}{l}\text { 17. Do not houseplant on Saturday because it will make the owner } \\
\text { unhappy. }\end{array}$ & 2.56 & .820 & $\mathrm{M}$ & 16 \\
\hline $\begin{array}{l}\text { 18. If one dreams of snake binding, it means that the single will find } \\
\text { the soulmate in the near future. }\end{array}$ & 3.00 & 1.258 & $\mathrm{M}$ & 9 \\
\hline 19. If a glass or a plate is broken, a bad thing will happen to a family. & 2.72 & 1.100 & $\mathrm{M}$ & 11 \\
\hline $\begin{array}{l}\text { 20. Number } 13 \text { is considered unlucky as it spells like ghost in Thai } \\
\text { when flips side. }\end{array}$ & 2.60 & 1.080 & M & 15 \\
\hline Total & 2.85 & .641 & $\mathrm{M}$ & \\
\hline
\end{tabular}

$* \mathrm{M}=$ Medium Level, $\mathrm{L}=$ Low Level

"if one wears an amulet, it is believed not to walk under the clothes line" $(\mathrm{M}=3.44$, S.D. $=1.003)$. In addition, participants rated item\#1 "it is not appropriate to wear black to visit the patient because black is a symbol of grief and death" as the third highest mean score $(\mathrm{M}=$ 3.32, S.D. = 1.069). On the other hand, item\#11 "do not clip one's nails at night as it will disturbancestors' spirits" was rated as the lowest mean score of superstitious beliefs in this present study. 
To compare mean differences of participants' origins, independent samples t-test was used for data analysis. Table 2 indicated no statistically significant difference between participants with different origins (Bangkok or upcountry) ( $\mathrm{t}=.167$, $\mathrm{p}=.869)$. Hence, the research hypothesis was rejected.

Table.2: Independent Samples T-Test of Superstitious Beliefs according to Origins

\begin{tabular}{|c|c|c|c|c|c|c|}
\hline & \multicolumn{2}{|c|}{$\begin{array}{c}\text { Bangkok } \\
(\mathbf{n = 1 4})\end{array}$} & \multicolumn{2}{c|}{$\begin{array}{c}\text { Upcountry } \\
(\mathbf{n = 1 1})\end{array}$} & \multicolumn{1}{c|}{$\boldsymbol{P}$} \\
\cline { 2 - 6 } & Mean & S.D. & Mean & S.D. & & .167 \\
\hline $\begin{array}{c}\text { Superstitious } \\
\text { Beliefs }\end{array}$ & 2.87 & .732 & 2.82 & .537 & .869 \\
\hline
\end{tabular}

\section{CONCLUSION, DISCUSSIONS, AND RECOMMENDATIONS}

The purposes of this study were to describe superstitious attitude and behaviors, examine level of superstitious beliefs of Thais, and compare mean differences between people with different origins (Bangkok and upcountry). In this study, aprevalence of superstitious beliefs of respondents was at a high level, which may be due to their stress of living and anxiety as they lived in a big city like Bangkok. This supported the previous findings of George and Sreedhar (2006) in which superstitious beliefs still exist in a modern world. Thus, steps should be taken to lessen some superstitious beliefs, and educate people to think rationally and scientifically.

Results of this present study found no statistically significant difference in superstitious beliefs between people with distinctive origins. This can be described that the questions in a scale measurement used to ask superstitious beliefs of this group were developed solely based on common or traditional beliefs in superstition, which cannot differentiate beliefs of people with distinguished origins. As most questions asked common superstations in Thailand, people consequently viewed these superstitious beliefs indifferently.

Like other studies, this present study had some limitation. Firstly, the samples were confined to graduate students at one public university, and the size was quite small. Thus, the generalizability of this study's findings was limited and needed to do with restriction. This study recommended that the expansion of sample size should be conducted in the further study. Secondly, even though the superstitious beliefs measurement scale used in this study was checked content validity and reliability with Cronbach's alpha test to ensure the quality of scale measurement, other validities such as construct validity and concurrent validity should be conducted through exploratory factory analysis (EFA) and confirmatory factor analysis (CFA) to check whether this scale relates to underling theoretical concepts.Thirdly, the scale measurement used in this study was mostly limited to common beliefsrather than specific superstitious beliefs such as good luck, bad luck, and animal related. Thus, the future research should focus on studying other areas of superstitious beliefs. The unsubstantiated belief inventory arranged by Sumaranjitha and Sreedhar (1992) encompassing five areas of irrational beliefs: curse, soul, omen, astrology, and prejudice should be utilized as the example to develop superstitious beliefs instrument for Thais in a future. Lastly, other variables relating to superstitious attitude and behaviors should be added in the further research since the three variables proposed in this current study may not be sufficient to test people's attitude and behaviors in superstition. The comparis on of socio-demographic variables in superstitious beliefs should also be conducted in a future study.

\section{ACKNOWLEDGEMENT}

I am very thankful to Rajamangala University of Technology Phra Nakhon for facility support and sponsorship for publication.

\section{REFERENCES}

[1] Best, J. W. (1997).Research in Education. Englewood Cliffs, NJ: Prentice - Hall, Inc.

[2] Charoensukmongkol, P. (2017). Superstitious behaviors and perceived job performance of internal auditing staffs in Thailand. Thammasat Review, 20(2), 18-38.

[3] Chinchanachokchai, S., Pusaksrikit, T., \& Pongsakornrungsilp, S. (2016). Exploring different types of superstitious beliefs in risk-taking behaviors: What we can learn from Thai consumers. Social Marketing Quarterly, 23(1), 47-63.

[4] Dayal, J. K. (2015). A study of superstitious attitude among women. International Journal of Scientific Research, 4(6), 657-658.

[5] Futrell, B. (2011). A closer look at the relationship between superstitious behaviors and trait anxiety. Rollins ndergraduate Research Journal, 5(2), 1-8.

[6] George, S. \& Sreedhar, K. P. (2006). Globalisation and the prevalence of superstitious beliefs. Journal of the Indian Academy of Applied Psychology, 32(3), 241-247. 
[7] Huque, M. \& Chowdhury, A. (2007). A scale to measure superstition. Journal of Social Sciences, $3(1), 18-23$.

[8] Kashiha, S. (2015). On the relationship between adolescents'tendency to superstition and the source of control. International Journal of Academic Research in Business and Social Sciences, 5(4), 134-145.

[9] Kramer, T.\& Block, L. (2008). Conscious and nonconscious components of superstitious beliefs in judgement and decision making. Journal of Consumer Research, 34, 783-793.

[10] Lakshmikanth, A. \& Hema, S. (2016). Superstitious around the world: A truth about myth. International Journal of Multidisciplinary Research and Development, 3(10), 193-196.

[11] Markel, D. T. (2005). The magic that binds us: Stress and superstition. Retrieved from https://getd.libs.uga.edu/pdfs/markle donald t 2007 $\underline{08 \text { ma.pdf }}$

[12] Mutlu, T. O., Öntürk, Y., Zorba, E., Karafil, A. Y., Yuldiz, K., \&Kartal, R. (2016). Analysis on some superstitious behaviors of university students engaging in tennis. Batman University Journal of Life Science, 6(1), 317-330.

[13] Nunnally, J. C. (1978). Psychometric theory. New York, NY: McGraw-Hill.

[14] Parinyaporn, S. (2016). Superstitions regarding animals: mutation and reincarnation in a Thai context.International Journal of Humanities and Social Science, 6(11), 168-174.

[15] Proebst, I. (2017). 10 curious superstitious you'll find in Thailand. Retrieved from https://theculturetrip.com/asia/thailand/articles/1 0-curious-superstitions-youll-find-in-thailnd

[16] Rabiei, K., Ghasemi, V., Arzani, H. (2013). Superstitin and culture diversity-case study: Isfahan province, Iran. Mediterranean Journal of Social Sciences, 4(4), 73-82.

[17] Saenko, I. (2005). The superstitions of today's college students. Russian Education \& Society, 47(12), 76-89.

[18] Shrivastav, M. (2017). A study of stress level contributing to the superstitious behavior. The International Journal of Indian Psychology, 4(3), 48-56.

[19] Sumaranjitha, L. \& Sreedhar, K. P. (1992).Unsubstantiated beliefs in adolescent girls. The Creative Psychologist, 4, 35-40.

[20] Vijay, T. S., Tripathi, P., \& Vijay, M. K. (2017). Superstitious beliefs among school teachers. International Journal of Home Science, 3(2), 613615.
[21] Zad, R. E. (2014). Superstitious beliefs and some of its causes (Case study: Ghachsaran citizens). Bulletin of Environment, Pharmacology and Life Sciences, 3(II), 286-290. 